\title{
Homocysteine in the Pathogenesis of Chronic Glaucoma
}

\author{
Mustafa R Kadhim ${ }^{1}$ and Colin I Clement ${ }^{2,3}$ \\ ${ }^{1}$ The Western Eye Hospital, London, \\ ${ }^{2}$ Glaucoma Unit, Sydney Eye Hospital, Sydney, \\ ${ }^{3}$ Central Clinical School, The University of Sydney, Sydney \\ ${ }^{1}$ United Kingdom \\ 2,3 Australia
}

\section{Introduction}

\subsection{Metabolic pathway}

Methionine is one of four amino acids that form succinyl CoA. This sulphur containing amino acid is the source of homocysteine (Hcy). It is converted to S-adenosylmethionine (SAM), the major methyl-group donor in one-carbon metabolism. The synthesis of SAM occurs when methionine condenses with adenosine triphosphate (ATP) by the hydrolysis of all three phosphate bonds. The methyl group attached to the tertiary group in SAM is activated and can be transferred to a variety of acceptor molecules, such as noradrenaline in the synthesis of adrenaline. The reaction product S-adenosylhomocysteine (SAH) is a simple thioether, analogous to methionine. The resulting loss of free energy accompanying the reaction makes the methyl transfer essentially irreversible. Next is the hydrolysis of SAH to Hcy and adenosine. Homocysteine has two fates. If there is a deficiency of methionine, Hcy may be re-methylated to methionine. If stores of methionine are adequate, Hcy may enter the trans-sulphuration pathway, where it is converted to cysteine. The re-synthesis of methionine occurs with the acceptance of a methyl group from N5-methyltetrahydrofolate (N5-methyl-THF) in a reaction that requires methyl-cobalamin, a coenzyme derived from cobalamin (vitamin B12). The methyl group is transferred from the B12 derivative to Hcy, and vitamin B12 is recharged from N5-methyl-THF. The synthesis of cysteine occurs when Hcy combines with serine, forming cystathionine, which is hydrolysed to $\alpha$ - ketobutyrate and cysteine. This sequence has the net effect of converting serine to cysteine and Hcy to $\alpha-$ ketobutyrate, which is oxidatively decarboxylated to form propionyl CoA. Because Hcy is synthesised from the essential amino acid methionine, cysteine is not an essential amino acid so long as methionine is available (Figure 1).

Under normal metabolic circumstances, there is a strict balance between Hcy formation and elimination. Usually about $50 \%$ of the Hcy formed is re-methylated to methionine. When protein or methionine intake is in excess, the trans-sulfuration pathway catabolises a larger proportion. If there is an increased formation of Hcy relative to its consumption, Hcy is excreted from the cells. This can be detected as an increased level of Hcy in plasma/serum or in the urine. 


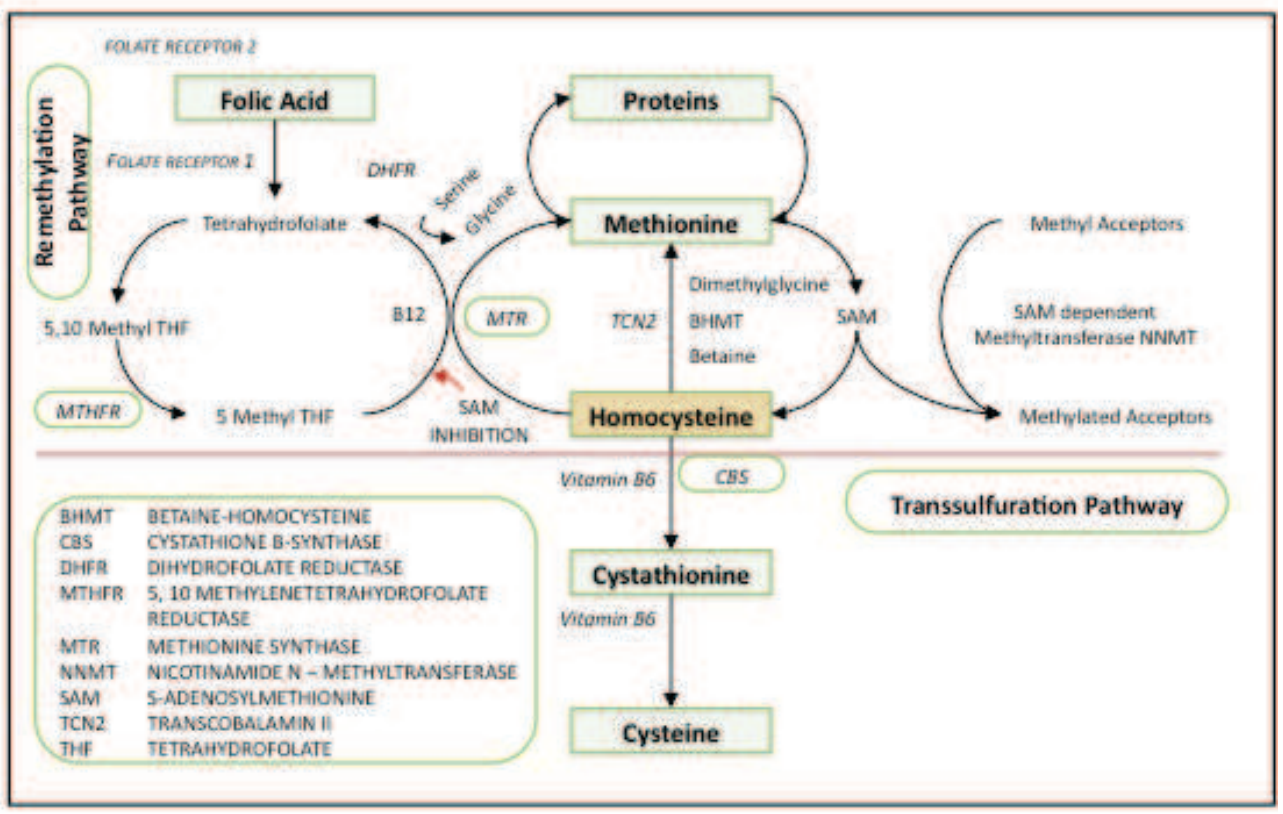

Fig. 1. Homocysteine Metabolism

\subsection{Genetic influences}

Homocysteine metabolism therefore has three key enzymes (Figure 1); methylenetetrahydrofolate reductase (MTHFR), cystathionine beta-synthase (CBS) and methionine synthesase (MTR).

The key enzyme in the remethylation pathway is MTHFR. Single nucleotide polymorphisms have been identified for this enzyme. The common $\mathrm{C} \rightarrow \mathrm{T}$ substitution at the 677 position results in decreased enzymatic function. This alanine to valine substitution, in heterozygotes, causes a 30\% drop in function, and with homozygotes, a $60 \%$ reduction. ${ }^{1}$ Deficiency of CBS deficiency likewise causes hyperhomocysteinaemia (HHcy), but the severity is less compared with vitamin B12 deficiency. This suggests the CBS enzyme is not as central to the total homocysteine (tHcy) level as the MTHFR enzyme.

The effect of the MTHFR genetic polymorphism has been scrutinized in a placebo controlled trial. ${ }^{2}$ The TT homozygous group for the mutation had a 2.4 times greater reduction in tHcy compared to wild type after $1 \mathrm{mg}$ of folic acid was given daily for three months, owing to the elevated baseline tHcy of TT group compared to CC and CT subgroups. This means MTHFR TT groups can be targeted for therapy. However, a British study ${ }^{3}$ of an older population described a regional difference in the tHcy even after adjustments for folate and vitamin B12 levels, smoking and the effect C677T polymorphism. This can only be explained by the effect of other unidentified genetic, systemic or environmental factors.

A secondary mutation of the MTHFR gene at position $1298 \mathrm{~A} \rightarrow \mathrm{C}$ also reduces function. Alone, this mutation confers no difference in the tHcy, but in combination with the $677 \mathrm{C} \rightarrow \mathrm{T}$ mutation, unsurprisingly, there is an elevation in the tHcy and decreased folate levels. ${ }^{4}$ 


\subsection{Systemic and environemental influences}

The effect of systemic disease, medications and environmental exposures on Hcy has been described in detail. 5 A summary is provided in Table 1.

\begin{tabular}{llll}
\hline \hline Reduced tHcy & $\begin{array}{l}\text { Moderate } \\
(15-30 \mu \mathrm{mol} / \mathrm{L})\end{array}$ & $\begin{array}{l}\text { Intermediate } \\
(30-100 \mu \mathrm{mol} / \mathrm{L})\end{array}$ & $\begin{array}{l}\text { Severe } \\
(>100 \mu \mathrm{mol} / \mathrm{L})\end{array}$ \\
\hline $\begin{array}{l}\text { Down syndrome } \\
\text { Pregnancy }\end{array}$ & $\begin{array}{l}\text { MTHFR C } \rightarrow \mathrm{T} \\
\text { homozygosity }\end{array}$ & Folate deficiency & Homocystinuria \\
$\begin{array}{l}\text { Folate excess } \\
\text { B12 Excess }\end{array}$ & $\begin{array}{l}\text { Male } \\
\text { Post-menopausal }\end{array}$ & Renal failure & $\begin{array}{l}\text { Vitamin B12 } \\
\text { deficiency }\end{array}$ \\
$\begin{array}{l}\text { Hyperthyroidism } \\
\text { Diabetes Mellitus } \\
\text { Exercise }\end{array}$ & $\begin{array}{l}\text { Coffee } \\
\text { Alcohol }\end{array}$ & & \\
\hline \hline
\end{tabular}

Table 1. Environmental and Systemic Influences on Homocysteine.

\section{Homocysteine assays}

Accurate measurement of Hcy requires a working knowledge of the plasma distribution. The vast majority is protein bound; the rest is free. This is further subdivided into Hcycysteine mixed disulphide, homocystine and Hcy. In combination they are tHcy.

Three types of assays have been used in Hcy-glaucoma studies: high performance liquid chromatography (HPLC), enzyme-linked immunoassays (EIA) and fluorescence polarization immunoassays (FPIA). The latter 2 give an estimation of the tHcy and are relatively easy to perform. ${ }^{5}$ In contrast, HPLC is more difficult to run and may have a much lower through put, but has the advantage of a broader analytical range and lower cost per test. Results from all 3 are comparable although there can be significant differences between methods and even between laboratories using the same method. ${ }^{6}$ Strategies to reduce the influence of inter-test variability should include running case and control assays simultaneously and using a single laboratory. Many Hcy-glaucoma studies have employed single laboratories but it is unclear whether testing was grouped or random. No method has demonstrated superiority over another.

\section{Homocysteine and systemic disease}

Injury to vascular endothelium, retinal ganglion cell apoptosis and extra-cellular matrix (ECM) remodelling of trabecular meshwork and/or lamina cribrosa may all contribute to optic nerve damage characteristic of glaucoma. All three events are linked with Hcy: the evidence is presented below.

\subsection{Cardiovascular disease}

In 1969, McCully ${ }^{7}$ highlighted a potential link between Hcy and cardiovascular disease (CVD) by observing pathological changes to blood vessels in 2 children. In both cases, gross vascular damage to arteries (small, medium and large); focal narrowing due to intimal and medial fibrosis and focal proliferation of peri-vascular connective tissue in the small vessels was noted in the setting of raised Hcy and cystathione. Since then, further animal and 
human research has shown a link between tHcy elevation and bioavailablity of endothelium-derived nitric oxide. ${ }^{8}$ Endothelium dependent vasodilation is significantly impaired in subjects with HHcy compared to controls. ${ }^{9}$ The early pathogenesis of atherosclerosis is related to this impairment of vasodilation, and HHcy exacerbates this. Even in healthy adults, a methionine load that produces transiently raised tHcy levels, impairs flow mediated endothelium dependent vasodilation. ${ }^{10}$

In vitro, it has been demonstrated that HHcy may cause vessel dysfunction via induced endothelial apoptosis. Apoptotic cell death in the endothelium via the unfolded protein response 11 and the detachment-mediated process ${ }^{12,13}$ are two possible mechanisms.

HHcy as a cardiovascular risk factor remains a contentious issue however. Observational studies have shown HHcy to be associated with an increased CVD risk, 14-17 though a causal role has been more difficult to confirm. A meta-analysis examining risk of ischaemic heart disease (IHD) and stroke found Hcy only a modest predictor in healthy populations. ${ }^{18}$ With a $25 \%$ reduction in Hcy an $11 \%$ reduction in IHD and 19\% reduction in stroke would occur if prospective data was used (the meta-analysis used retrospective data that may have suffered from reverse-causality) in the presence of adjustment for other known CVD risk and correction for regression dilution bias is performed.

Several randomized control trials (RCTs) on therapeutic reduction of Hcy in cardiovascular disease have been conducted; they typically use folate, vitamin B6 and B12 supplements as intervention. A meta-analysis of RCTs shows no significant difference between intervention and control groups. ${ }^{19}$ Another large study ${ }^{20}$ did not show a benefit in taking B group vitamins and folate verses placebo in those who has suffered a cerebrovascular event (ischaemic stroke, transient ischaemic attack or intracerebral haemorrhage). There was no reduction in the relative risk for non-fatal / fatal stroke, myocardial infarction or any other death from a vascular cause. The meta-analysis by Bazzano et $\mathrm{al}^{21}$ similarly found all-cause mortality as well as CVD was not improved with folic acid supplementation amongst those with a prior history of vascular disease.

\subsection{Homocysteine and apoptosis}

As mentioned, evidence that Hcy induces vascular endothelial cell apoptosis exists.11-13 Similar findings have been reported in neuronal tissue experiments as well. For example, Hcy stimulation of the N-methy-D-aspartate (NMDA) receptor of cerebellar granule cells has been shown to induce their death. ${ }^{22}$ Importantly, this finding has been replicated for retinal ganglion cells (RGC). Moore et $\mathrm{al}^{23}$ have shown intravitreal injection of homocysteine causes RGC apoptosis in vivo. Higher doses of homocysteine were associated with more widespread RGC apoptosis. In more recent work, Ganapathy et $\mathrm{al}^{24}$ assessed mouse RGC cell culture response to Hcy exposure. They found marked RGC apoptosis in the presence of Hcy, a response that was significantly reduced by co-application of MK-801 (NMDAreceptor blocker). Homocysteine was also found to significantly increase intracellular calcium as well as reactive species superoxide, nitric oxide and peroxynitrite.

These studies in themselves do not constitute direct evidence that Hcy causes neuronal apoptosis. They do however suggest Hcy has the potential to do so through activation of NMDA-mediated intracellular pathways. Strategies that target Hcy and/or NMDAreceptors may potentially block this response and have therapeutic potential in glaucoma. Further work is need in this area. 


\subsubsection{Dementia and neurodegeneration}

Given chronic glaucoma is characterised by progressive RGC apoptosis, it may be considered a form of neurodegeneration. Both chronic glaucoma and other neurodegenerative diseases, such as Alzheimer's disease (AD), similarly occur in predominantly elderly populations. A common aetiology is possible.

It is interesting to note the recent observation that Hcy is a biomarker for neurodegenerative disease and useful in identifying patients with B vitamin deficiency. ${ }^{25}$ It has been shown that clinical symptoms of cognitive impairment and missing ankle tendon jerks are associated with patients with low vitamin B12 concentrations. ${ }^{26}$

A recent cohort study has demonstrated a correlation between polyneuropathy or dementia and increased tHcy in a geriatric population. ${ }^{27}$ Similar findings were reported in an earlier study of neurodegenerative disorders, thus raising the possibility that Hcy has neurotoxic effects. These findings are consistent with laboratory data demonstrating neuronal apoptosis induced by Hcy as discussed above. However, given the apparent association between Hcy and CVD plus the role vascular disease plays in dementia and polyneuropathy, 28 it is difficult to know whether HHcy is causal or merely an association.

Evidence in support of a causal relationship between Hcy and neurodegeneration comes from a study examining central nervous system (CNS) atrophy with magnetic resonance imaging. ${ }^{29}$ Patients aged over 70 years with mild cognitive impairment were randomised to receive either high-dose folic acid, vitamins B6 and B12 $(n=85)$ or placebo $(n=83)$ for 2 years. The mean rate of CNS atrophy per year was $0.76 \%$ [95\% CI, 0.63-0.90] in the active treatment group and $1.08 \%$ [0.94-1.22] in the placebo group $(P=0.001)$. The treatment response was related to baseline Hcy levels: the rate of atrophy in participants with Hcy $>13$ $\mu \mathrm{mol} / \mathrm{L}$ was $53 \%$ lower in the treatment group $(P=0.001)$. Whether the findings result from reduced Hcy, neuroprotective effects of folic acid, vitamin B6 and/or vitamin B12, improved CNS blood flow or some other mechanism is not clear. It does, however, raise the possibility that Hcy is involved in the neurodegenerative process.

\subsubsection{Extracellular matrix remodelling}

Extracellular matrix remodeling by Hcy is interesting because of implications for glaucoma pathogenesis. Effects on vascular tissues of the optic nerve head in addition to the trabecular meshwork or lamina cribrosa could result in glaucoma development or progression. There is no evidence to directly support this theory but findings in non-ocular tissue suggest a potential role. Human vascular smooth muscle cells from cardiomyopathic hearts demonstrate premature atherosclerosis when exposed to Hcy. ${ }^{30}$ This is in association with significant up-regulation of collagen expression and $\alpha$-actin. The response is potentially mediated through induced matrix metalloproteinase (MMP)-2, -4 and -9 activity as well as increased nitrotyrosine expression. ${ }^{31-33}$

\section{Homocysteine and ocular vascular disease}

Although the exact pathogenesis of glaucomatous optic neuropathy is unknown, impaired blood flow to the optic nerve head may play a role. ${ }^{34,35}$

Compromised optic nerve head perfusion may, in part, be due to the action of plasma Hcy. Raised tHcy causes overproduction of free radicals, intimal damage, matrix metalloproteinase up regulation and lysis of elastin or collagen in arterial media. 36,37 These effects are strongly linked with systemic vasculopathy including coronary artery disease, 
aortic aneurysm, peripheral vascular disease and stroke. Similar events are likely to affect the microcirculation of the eye, including the optic nerve head.

Such associations have been described for a number of ocular vascular conditions. These are summarized below.

\subsection{Retinal artery and vein occlusion}

There have been numerous studies examining the association between raised plasma Hcy and retinal vascular occlusions. For instance, Moghimi et $\mathrm{al}^{38}$ have demonstrated in an Iranian population, elevated plasma Hcy in retinal vein occlusion compared to control (14.76 vs $11.42 \mu \mathrm{mol} / \mathrm{l})$. This is similarly the case in Indian, ${ }^{39}$ North American, ${ }^{40}$ Italian $^{41}$ and Chinese ${ }^{42}$ studies. These findings are supported by data from the Blue Mountains Eye Study (Australia) demonstrating a significant correlation between vein occlusion and Hcy. ${ }^{43}$

Meta-analysis of Hcy in retinal vein occlusion has recently been performed. ${ }^{44}$ In all, there were 1533 cases of retinal vein occlusion and 1708 controls where plasma Hcy was assessed. Individuals with vein occlusion had, on average, tHcy $2.8 \mu \mathrm{mol} / \mathrm{L}$ higher than the control group. It was concluded that evidence supports the role of Hcy in retinal vein occlusion but that publication bias and study heterogeneity were potential confounders. As for the cause for HHcy in these patients, the reason was not clear. The role of MTHFR mutation was examined but no correlation found. Environmental factors are likely to be important.

The literature on Hcy and retinal artery disease largely consists of small studies with fewer than 50 patients. One of the largest is a retrospective study of 105 patients with retinal artery occlusion. ${ }^{45}$ This study found significant elevation of tHcy compared with the same number of controls. Mutation of MTHFR was also examined but no significant association could be found. Other notable studies ${ }^{46,47}$ have reported similar findings and population based analysis from the Blue Mountains Eye Study also suggests HHcy and retinal artery emboli are weakly associated. 48 A small meta-analysis ${ }^{49}$ suggests HHcy is more common in retinal artery occlusion but again no correlation with MTHFR mutation was found.

\subsection{Choroidal neovascularization}

Choroidal neovascularization (CNV), as seen in age-related macular degeneration (AMD), is a process of vascular proliferation beneath the retinal pigment epithelium and sub-retinal space. Risk factors are numerous and include cigarette smoking, lack of exercise, low fruit consumption, hypercholesterolaemia, increasing age and genetic susceptibility (eg: compliment factor $\mathrm{H}) .50,51$

A comprehensive epidemiological review shows links between CVD and AMD. 52 Analysis of data from the Framingham Eye Study and Beaver Dam Study, provides evidence that CVD and AMD share a similar risk profile (such as age, smoking, hypertension, hypercholesterolemia, post-menopausal estrogen use, diabetes, and dietary intake of fats, alcohol and antioxidants). In the same analysis, Hcy and vitamin B compounds were independent risk factors for both CVD and AMD.

Homocysteine as a risk factor for CNV development has been confirmed in a number of studies. Axer-Siegel et al ${ }^{53}$ reported a significantly increased frequency of HHcy in patients with neovascular AMD (44.1\%) compared to dry AMD (22.4\%) and age-matched controls (21.4\%). Several other groups have confirmed this finding. 54,55 


\subsection{Diabetic retinopathy}

The Wisconsin epidemiological study of diabetic retinopathy, 56 spanning from 1979 until 2007, looked at patients with type 1 diabetes mellitus. In the 1990-1992 prevalence data, Hcy was associated with increased odds of more severe diabetic retinopathy and presence of macular oedema. Many studies since have confirmed this association for type 2 diabetes mellitus as well. $57-59$

It is also true that severity of retinopathy correlates strongly with Hcy level, independent of glycaemic control. ${ }^{60}$ Higher Hcy levels are observed in individuals with proliferative retinopathy compared to non-proliferative retinopathy, even though in both instances the levels are significantly elevated compared to control. This occurs despite similar baseline plasma glucose measurements and comparable frequencies of CVD (hypertension, ischaemic heart disease, cerebrovascular accident, thromboembolic event).

More recently, plasma and vitreous Hcy has been measured in patients with proliferative diabetic retinopathy. ${ }^{61}$ Samples taken at the time of intra-ocular surgery showed mean elevation of both Hcy sample groups (plasma $16.04 \pm 2.75 \mu \mathrm{mol} / \mathrm{L}$; vitreous $3.64 \pm 0.65$ $\mu \mathrm{mol} / \mathrm{L})$ compared to non-diabetic controls. This both supports the outcomes of other studies on tHcy in diabetes and provides evidence of impaired blood-retina barrier in these patients. It is unclear what effect elevated vitreal Hcy has on disease progression.

There is conflicting evidence on the role of MTHFR mutation as a determinant of HHcy in diabetic retinopathy. A large study in Chinese patients ${ }^{62}$ showed the MTHFR T allele was present in $49.09 \%$ of cases with diabetic retinopathy. This was significantly higher than in individuals with diabetes without retinopathy (33.16\%) or no diabetes at all (31.58\%). It has been suggested that homozygous mutation of MTHFR is associated with premature onset of diabetic retinopathy only in the presence of homozygous methionine synthase reductase mutation. ${ }^{63}$ However, in a case series from Turkey, ${ }^{64}$ no association between MTHFR C677T mutation and HHcy with retinopathy or neuropathy could be found. It is unclear whether such differences reflect ethnic variation, result from differences in study design or are influenced by other unidentified factors.

\subsubsection{Non-Arteritic Ischaemic Optic Neuropathy (NAION)}

In terms of pathophysiology, non-arteritic ischaemic optic neuropathy (NAION) and chronic glaucoma share a common mechanism. Both display deficiencies in optic nerve head perfusion although the mechanism is much less certain with chronic glaucoma. The event in NAION may represent a watershed infarct of retro-laminar optic nerve head tissue in individuals with compromised short posterior ciliary arteries and risk factors that include a crowded disc, poorly overlapping vascular fields, nocturnal hypotension and hypoxia. 65 Some risk factors are common to chronic glaucoma and typically ante cede both conditions by many years. However, whilst NAION is an acute condition, chronic glaucoma is not.

Given that impaired circulation is central to the development of NAION, it seems logical that HHcy might play a role. This has borne out in several studies examining associations between the two. Pianka et al ${ }^{66}$ reported elevated levels in $45 \%$ of 40 NAION patients (mean age 66 years) but in only $9.8 \%$ of control subjects. Similar findings have been reported by Giambene et al $^{67}$ and Weger et al. ${ }^{68}$

However, some studies have questioned the association. Both Kawasaki et al ${ }^{69}$ in a study of 17 patients and Biousse et $\mathrm{al}^{70}$ in a study of 14 patients failed to find any significant association with Hcy. One might criticise these studies on the basis of small participant 
numbers but it is noteworthy that both patient cohorts were relatively young. This is interesting given plasma Hcy levels increase with age. 5 This raises the possibility that Hcy becomes increasingly important in NAION development with increasing age and again points to similarities with chronic glaucoma. Further research is required in this area.

\subsection{Ocular Ischaemic Syndrome}

Ocular ischemic syndrome (OIS) is the name given to the ocular symptoms and signs attributable to chronic, severe carotid artery obstruction, although chronic ophthalmic artery obstruction can cause a similar clinical picture. Atherosclerosis is the most common aetiology, but possible causes include Eisenmenger syndrome, giant cell arteritis, and other inflammatory conditions. Most patients are older than 55 years of age. Typically, a $90 \%$ or greater ipsilateral obstruction is necessary to cause the ocular ischemic syndrome. Both eyes are involved in about $20 \%$ of cases. Iris neovascularization is the most common anterior segment finding at diagnosis and typical fundus signs include retinal arteriole narrowing, retinal venous dilatation without tortuosity, midperipheral retinal haemorrhages and microaneurysms, and peripheral vascular closure.

Little information is available linking OIS with HHcy. A case described of bilateral OIS71 without carotid artery stenosis and normal cardiovascular and biochemical markers had a markedly elevated tHcy of $20.8 \mu \mathrm{mol} / 1$ as the only abnormality. No larger studies have been published to confirm or deny this association.

\section{Plasma homocysteine and chronic glaucoma}

Chronic glaucoma may, in part, be the manifestation of abnormal optic nerve head perfusion. This is supported by evidence showing altered flow dynamics within the ophthalmic and retinal arteries of patients with glaucoma, an association between glaucoma and vascular disease, and acceleration of the glaucomatous process in the presence of nocturnal hypotension. Evidence also indicates glaucoma is a process of retinal ganglion cell apoptosis, which may in turn be related to or independent of optic nerve head perfusion.

Homocysteine potentially contributes to glaucoma pathogenesis via both mechanisms. Unsurprisingly, many studies have examined the role of Hcy in glaucoma over the past decade. However, there are inherent difficulties in comparing studies on tHcy. The work in relation to glaucoma is no exception. The main challenges relate to the way Hcy is measured, study design and differences in populations studied.

Despite the large number of Hcy-glaucoma studies, collectively they report on a relatively confined population. A significant number of studies have been in Turkish cohorts. German studies also contribute significantly to the overall number. The German studies are from the same group and presumably represent the same population.

There are also reports from Israel, Australia, USA, Italy and Pakistan. We have no results from populations in Asia, Africa or South America. Interestingly, there is also little data published from Scandinavia. Given the findings in pseudoexfoliation glaucoma (PXFG) and high prevalence of PXFG in this region, one would expect both interest and opportunity to conduct studies there. There has been a report on tHcy in pseudoexfoliation syndrome and PXFG combined from Finland; ${ }^{72}$ we are not aware of any studies specifically reporting glaucoma.

The main determinants of mildly elevated plasma homocysteine remain poor diet, vegetarianism, low folate, low cobalamin, MTHFR mutation, renal impairment and 
medications ${ }^{5}$. Whilst the majority of Hcy-glaucoma studies control for the effects of medication and renal impairment, much less is known about the caloric intake of the study participants or folate/cobalamin status. Differences in diet are likely to be real but the impact is unknown in glaucoma research.

A few studies have reported folate and vitamin B status and point to significant differences between populations. Participants in an Italian study ${ }^{73}$ were found to have high normal folate and mid normal vitamin B12 whereas 2 studies from Turkey have low normal vitamin B12 with normal ${ }^{74}$ or depleted folate. ${ }^{79}$ In at least 1 of these studies, ${ }^{74}$ it is clear that some participants were vitamin B12 deficient as well. As the influence of folate and vitamin B12 on plasma homocysteine is non-linear, ${ }^{5}$ these differences could amount to considerable variations in plasma homocysteine. For example, vitamin B12 in the mid normal range is associated with mean plasma homocysteine around $10-11 \mu \mathrm{mol} / \mathrm{L}$ compared to $14 \mu \mathrm{mol} / \mathrm{L}$ for vitamin B12 at the lower limit of normal. ${ }^{5}$ Individuals that are vitamin B12 deficient can have plasma homocysteine near $20 \mu \mathrm{mol} / \mathrm{L}$. Similarly, the difference in folate levels reported by Turgut ${ }^{74}$ and $\mathrm{Cumurcu}^{78}$ can amount to an almost doubling of plasma homocysteine. ${ }^{5}$ Despite researchers best efforts, we are not comparing like with like.

Only a handful of the reports on Hcy and glaucoma are sufficiently powered to detect the outcome they describe. Sample size calculation, assuming the need to detect a $2 \mu \mathrm{mol} / \mathrm{L}$ difference, standard deviation of $3 \mu \mathrm{mol} / \mathrm{L}$, a power of $90 \%$ and significance set at 0.05 , requires a sample size of at least 48 cases per group. In studies where standard deviation exceeds $9 \mu \mathrm{mol} / \mathrm{L}$ (Table 2), 426 cases would be required to detect a significant difference. Clearly, these criteria have not been met in most studies.

\begin{tabular}{|c|c|c|c|c|c|c|c|}
\hline Author & Year & Design & Number & Location & Assay & $\begin{array}{l}\text { Homocysteine } \\
(\mu \mathrm{mol} / \mathrm{L})\end{array}$ & Elevated \\
\hline Tranchina 73 & 2011 & Prospective & 36 & Italy & EIA & $16.55 \pm 7.23$ & Yes \\
\hline Turgut 74 & 2010 & Prospective & 34 & Turkey & HPLC & $15.46 \pm 9.27$ & Yes \\
\hline Clement $^{75}$ & 2009 & Prospective & 48 & Australia & FPIA & $11.77 \pm 4.18$ & Yes \\
\hline Roedl76 & 2007 & Prospective & 30 & Germany & HPLC & $14.51 \pm 4.43$ & Yes \\
\hline Roedl77 & 2007 & Prospective & 70 & Germany & HPLC & $13.77 \pm 4.13$ & Yes \\
\hline Cumurcu78 & 2006 & Prospective & 24 & Turkey & EIA & $14.88 \pm 3.26$ & Yes \\
\hline Saricaoglu 79 & 2006 & Prospective & 20 & Turkey & EIA & $18.50 \pm 4.50$ & Yes \\
\hline Turacli 80 & 2005 & Prospective & 60 & Turkey & FPIA & $15.76 \pm 5.55$ & No \\
\hline Altinta 81 & 2005 & Prospective & 22 & Turkey & FPIA & $14.96 \pm 4.55$ & Yes \\
\hline Bleich 82 & 2004 & Prospective & 29 & Germany & EIA & $15.53 \pm 7.76$ & Yes \\
\hline Leibovitch 83 & 2003 & Prospective & 30 & Israel & HPLC & $16.80 \pm 3.20$ & Yes \\
\hline Vessani ${ }^{84}$ & 2003 & Prospective & 50 & USA & FPIA & $10.1^{*}$ & Yes \\
\hline Bleich $^{85}$ & 2002 & Prospective & 19 & Germany & EIA & $11.61 \pm 3.74$ & Yes \\
\hline
\end{tabular}

* Standard Deviation not reported

Table 2. Homocysteine and Pseudoexfoliation Glaucoma (PXFG)

\subsection{Pseudoexfoliation glaucoma}

Pseudoexfoliation syndrome is a multi-system disorder of cellular metabolism resulting in random synthesis of extracellular fibrillar material. The main clinical manifestation is in the eye where fibrillar material can be seen on the lens capsule and pupil margin. Affected individuals have a weak lens capsule and zonules and have poor mydriasis. They are at 
significant risk of developing raised IOP with associated glaucoma (PXFG) but glaucoma has also been reported despite apparently normal IOP.

PXFG shares many common associations with homocysteine. Cardioavascular disease 84 , oxidative stress ${ }^{87}$ increased prevalence with age and Alzheimer's disease 88,89 are common to both: a pathogenic link has been proposed. ${ }^{90}$ This is supported by research showing exfoliation material contains laminin, elastin and fibrillin, components of extracellular matrix metabolism under the influence of homocysteine.

All studies looking at the association between PXFG and plasma homocysteine have demonstrated significant elevation with the exception of Turacli et al ${ }^{80}$ (Table 2). This is the most consistent finding in homocysteine-glaucoma research and has occurred despite different assays and study populations across four continents. The control group in the Turacli et al study had the highest mean plasma homocysteine level $(17.43 \mu \mathrm{mol} / \mathrm{L} ; 67.6 \%$ with hyperhomocysteinaemia) of any study on glaucoma reported in the literature. Clearly this rate of hyperhomocysteinaemia in the general population is abnormal and makes detection of homocysteine elevation difficult in different cohorts.

The findings in PXFG are strongly suggestive that Hcy is a factor in its pathogenesis. Attention should shift now towards larger population-based studies and clinical trials to confirm this association and assess response to intervention (folate and vitamin B12). The prospect of an intervention that is taken orally, is cheap and with few side effects is an exciting prospect.

\subsection{Primary open angle glaucoma}

Studies are divided on the issue of plasma Hcy and POAG (Table 3). Equal numbers report a statistically significant correlation or no correlation at all. It is suggested that differences in Hcy assays, study design and populations sampled underlie these outcomes. The effect of assays can largely be discounted for 3 reasons: i) HPLC, EIA and FPIA are comparable tests, 5 ii) in each study POAG and control samples were analyzed using the same technique and laboratory, and iii) the findings for PXFG have been so consistent despite the use of different assays.

\begin{tabular}{|c|c|c|c|c|c|c|c|}
\hline Author & Year & Design & Number & Population & Assay & $\begin{array}{c}\text { Homocysteine } \\
(\mu \mathrm{mol} / \mathrm{L})\end{array}$ & Elevated \\
\hline Tranchina ${ }^{73}$ & 2011 & Prospective & 40 & Italy & EIA & $13.91 \pm 3.61$ & No \\
\hline Turgut 74 & 2010 & Prospective & 34 & Turkey & HPLC & $11.28 \pm 4.80$ & No \\
\hline Michael $^{90}$ & 2009 & Prospective & 70 & Pakistan & EIA & $15.20 \pm 1.28$ & Yes \\
\hline Clement ${ }^{75}$ & 2009 & Prospective & 36 & Australia & FPIA & $11.21 \pm 2.84$ & Yes \\
\hline Roedl91 & 2008 & Prospective & 36 & Germany & HPLC & $13.43 \pm 3.53$ & Yes \\
\hline Roedl92 & 2007 & Prospective & 39 & Germany & HPLC & $13.93 \pm 4.59$ & Yes \\
\hline Cumurcu$^{78}$ & 2006 & Prospective & 25 & Turkey & EIA & $9.22 \pm 3.70$ & No \\
\hline Altinta 81 & 2005 & Prospective & 19 & Turkey & FPIA & $11.91 \pm 4.38$ & No \\
\hline Wang93 & 2004 & Retrospective & 55 & USA & HPLC & $14.90 \pm 6.45$ & No \\
\hline Bleich 85 & 2002 & Prospective & 18 & Germany & EIA & $12.52 \pm 3.62$ & Yes \\
\hline
\end{tabular}

Table 3. Homocysteine and Primary Open Angle Glaucoma (POAG)

It is however, quite reasonable to suggest study design and population sampled are significant factors. Given the sample size calculations already mentioned, it seems hardly 
surprising some studies have had a negative outcome. In this respect, it is interesting to note that 3 of 5 studies reporting no significant association actually demonstrated small 78 or considerable 74,81 differences in plasma homocysteine between POAG and control. This is confounded by large variance in the population (as shown by standard deviation) and high mean plasma homocysteine in controls.

\subsection{Normal tension glaucoma}

Non-IOP dependent factors are of particular interest in normal tension glaucoma (NTG). Work has focused on optic nerve head perfusion and its influences including atherosclerotic disease, systemic hypertension, use of anti-hypertensive agents and vasospastic disorders (eg: migraine, Raynaud's phenomenon). Similarly, retinal ganglion cell apoptosis might play a role. Homocysteine has the potential to contribute to NTG pathogenesis via both pathways: as a mediator of vascular injury leading to impaired optic nerve head perfusion and as an excitatory amino acid triggering RGC apoptosis. 23,24

Five studies have reported on plasma homocysteine in NTG (Table 4). With the exception of Clement et $\mathrm{al}^{75}$ none have found a statistically significant association. However, closer examination of these data is needed. Both Turgut et al74 and Cumurcu et al78 reported increased plasma homocysteine in NTG though it did not reach statistical significance. Levels in NTG were $29.8 \%$ and $23.7 \%$ higher than control compared to $19.6 \%$ as reported by Clement et al. Again, sample size plays a role here. Both studies are significantly underpowered to detect a difference given the high standard deviation reported.

It may be the case that homocysteine is not associated with NTG. However, based on the scope and quality of research currently available, no conclusions can be made yet. Further work is needed to clarify this issue.

\begin{tabular}{cccccccc}
\hline \hline Author & Year & Design & Number & Population & Assay & $\begin{array}{c}\text { Homocysteine } \\
(\mu \mathrm{mol} / \mathrm{L})\end{array}$ & Elevated \\
\hline Rossler $^{44}$ & 2010 & Prospective & 42 & Germany & FPIA & $10.95 \pm 2.65$ & No \\
Turgut $^{74}$ & 2010 & Prospective & 48 & Turkey & HPLC & $11.27 \pm 4.91$ & No \\
Clement $^{75}$ & 2009 & Prospective & 34 & Australia & FPIA & $11.74 \pm 3.79$ & Yes \\
Cumurcu $^{78}$ & 2006 & Prospective & 19 & Turkey & EIA & $10.39 \pm 3.89$ & No \\
Vessani $^{84}$ & 2003 & Prospective & 25 & USA & FPIA & $9.1^{*}$ & No \\
\hline \hline
\end{tabular}

* Standard Deviation not reported

Table 4. Homocysteine and Normal Tension Glaucoma (NTG)

\subsection{Primary angle closure glaucoma}

The proposed mechanism by which raised homocysteine contributes to primary angle closure glaucoma (PACG) differs significantly from PXFG, POAG and NTG. Much less emphasis has been placed on the role of homocysteine in ocular circulation, RGC apoptosis and trabecular meshwork remodelling. Instead, the effect on extracellular matrix remodelling of other anterior segment structures has been promoted. 90 This is on the basis that patients with PACG have reduced MMP-2 and MMP-9 expression in Tenon's capsule and Hcy has demonstrable effects on MMP expression.

The only study reporting plasma Hcy in PACG (Table 5) showed significant elevation compared with POAG and control. 90 The same report demonstrated increased frequency of 
C677T and A1298C MTHFR polymorphisms. However, closer analysis shows MTHFR mutations are frequent in 1 ethnic group (Punjabi) but not the other (Pathan). Unfortunately, Hcy levels within each ethnic group are not stated. A difference between the two would suggest i) Hhcy is not associated with PACG but may occur in parallel in some populations due to certain factors (eg: MTHFR polymorphisms) ii) the anterior segment remodelling theory is unlikely. In the absence of such data we can only speculate. We await other studies with interest.

\begin{tabular}{cccccccc}
\hline \hline Author & Year & Design & Number & Population & Assay & $\begin{array}{c}\text { Homocysteine } \\
(\mu \mathrm{mol} / \mathrm{L})\end{array}$ & Elevated \\
\hline Michael $^{90}$ & 2009 & Prospective & 48 & Pakistan & EIA & $20.8 \pm 4.8$ & Yes \\
\hline \hline
\end{tabular}

Table 5. Homocysteine and Primary Angle Closure Glaucoma (PACG)

\section{MTHFR mutation and chronic glaucoma}

MTHFR mutation is of interest given its role as the major genetic determinant of raised plasma Hcy. Increased mutation rates could help explain the finding of raised plasma Hcy in some glaucoma patients. Studies have reported on the frequency of MTHFR C677T mutation, and to a lesser extent A1298C, in different types of glaucoma (Table 6).

\begin{tabular}{cccc}
\hline \hline Author & Year & Glaucoma & Increased Frequency \\
\hline Clement $^{75}$ & 2009 & PXFG & No \\
Fan $^{95}$ & 2008 & PXFG & No \\
Fingert $^{96}$ & 2006 & PXFG & No \\
Mossbock $^{97}$ & 2006 & PXFG & No \\
\hline Fan $^{98}$ & 2010 & POAG & No \\
Michael $^{90}$ & 2009 & POAG & No \\
Clement $^{75}$ & 2009 & POAG & No \\
Michael $^{99}$ & 2008 & POAG & No \\
Zetterberg100 $_{\text {Mabuchi }}{ }^{101}$ & 2007 & POAG & No \\
Fingert $^{96}$ & 2006 & POAG & No \\
Mossbock $^{97}$ & 2006 & POAG & No \\
Junemann $^{102}$ & 2006 & POAG & No \\
Bleich $^{85}$ & 2005 & POAG & Yes \\
Clement $^{75}$ & 2002 & POAG & Yes \\
Woo & 2009 & NTG & No \\
Mabuchi $^{101}$ & 2009 & NTG & Yes \\
\hline Michael $^{90}$ & 2006 & NTG & No \\
Michael $^{99}$ & 2009 & PACG & Yes \\
\hline \hline
\end{tabular}

Table 6. MTHFR Mutation and Chronic Glaucoma

Although, there is a large body of evidence supporting a role for Hcy in the pathogenesis of PXFG, there are few studies on MTHFR mutation in this condition. Despite this, the findings have been universal: MTHFR mutation is not a risk factor for PXFG. Raised plasma Hcy is due to other factors in these patients. 
Most MTHFR mutation research in glaucoma has been on POAG. Despite the inconsistent findings regarding Hcy, studies generally agree MTHFR mutation does not occur at an increased rate in POAG. Two studies 85,102 have reported MTHFR C677T mutation is a risk factor for POAG. Both are from the same research group. It is unclear whether this data is from the same cohort of patients.

Fewer studies have examined MTHFR mutation in NTG. For this reason, it is hard to make a sensible conclusion. At this stage, it seems MTHFR is not likely to be a risk factor for NTG but further research is needed.

Two reports on PACG suggest an association. In both studies 90,99 from the same group, the association was seen in only one ethnic subgroup (Pakistani Punjabi). The significance of this is uncertain without corroborating evidence from other groups examining different populations.

\section{Conclusion}

There is now a substantial body of literature on Hcy and glaucoma. Although there is general agreement that Hcy is raised in patients with PXFG, the findings have been less consistent for other types of chronic glaucoma. The reason for this is not entirely clear but may, in part, relate to study design and population differences.

The findings in PXFG, and to a lesser extent with other chronic glaucoma, suggest therapeutic intervention might be an option in these patients. Plasma Hcy may be lowered by supplemental folate and vitamin B12: both are readily available, cheap and have few side effects. Benefit is likely to be derived from positive effects on vascular health, in particular optic nerve head perfusion. Reduced RGC apoptosis is another potential outcome. No studies have yet examined the effect of taking these supplements on glaucoma progression.

With respect to treating raised Hcy in glaucoma, there are two areas of concern. First, the level of Hcy required to start treatment is ill defined. Although raised compared to control, most research quotes mean Hcy levels within the normal reference range. For example, our study ${ }^{75}$ found HHcy (female $>12 \mu \mathrm{mol} / \mathrm{L}$; male $>14 \mu \mathrm{mol} / \mathrm{L}$ ) in $27.6 \%, 30.6 \%$ and $29.4 \%$ of patients with PXFG, POAG and NTG respectively. This means two-thirds of patients return what is considered a normal Hcy reading. What do we do here? Options include treating only those with raised Hcy by laboratory definition, reducing the threshold for treatment or treating everyone irrespective of Hcy level. Clinical trials measuring glaucoma progression following folate and vitamin B12 supplementation relative to Hcy level will help define this better.

Secondly, and more worrying, is the observation in the cardiovascular literature that interventions that reduce Hcy have little benefit. ${ }^{19}$ This is despite the consistent observation that raised Hcy is a risk factor for CVD. This points to a similar outcome in glaucoma research. However, glaucoma pathogenesis is multi-factorial and optic nerve head perfusion is only part of the story. Homocysteine, and strategies to lower it, can potentially have direct actions on the optic nerve (ie: apoptosis of RGCs) and structures that support it (ie: ECM remodeling). We have been encouraged by the outcomes in $\mathrm{AD}$ research ${ }^{29}$ showing benefit from supplemental folate and vitamin B12 intake.

\section{Acknowledgment}

The authors wish to thank Mr Haider Twaij for assistance with Figure 1. 


\section{References}

[1] Miyaki K. Genetic polymorphisms in homocysteine metabolism and response to folate intake: A comprehensive strategy to elucidate useful genetic information. J Epidemiol. 2010; 20: 266-70.

[2] Miyaki K, Murata M, Kikuchi $\mathrm{H}$ et al. Assessment of tailor-made prevention of atherosclerosis with folic acid supplementation: Randomized, double-blind, placebo-controlled trials in each MTHFR C677T genotype. J Hum Genet 2005; 50: 241-8.

[3] Dekou V, Whincup P, Papacosta O et al. The effect of the C677T and A1298C polymorphisms in the methylenetetrahydrofolate reductase gene on homocysteine levels in elderly men and women from the british regional heart study. Atherosclerosis. 2001; 154: 659-66.

[4] Van Der Put NMJ, Gabreëls F, Stevens EMB et al. A second common mutation in the methylenetetrahydrofolate reductase gene: An additional risk factor for neural-tube defects? Am J Hum Genet. 1998; 62:1044-51.

[5] Refsum H, Smith AD, Ueland PM et al. c Clin Chem 2004 50: 3-32.

[6] Pfeiffer CM, Huff DL, Smith SJ et al. Gunter Comparison of Plasma Total Homocysteine Measurements in 14 Laboratories: An International Study Clin Chem 1999; 45: 12618

[7] McCully KS. Vascular pathology of homocysteinemia: Implications for the pathogenesis of arteriosclerosis. Am J Pathol. 1969; 56: 111-28

[8] Zhang X, Li H, Jin $\mathrm{H}$ et al. Effects of homocysteine on endothelial nitric oxide production. Am J Physiol - Renal Physiol. 2000; 279: F671-8

[9] Tawakol A, Omland T, Gerhard M et al. Hyperhomocysteinemia is associated with impaired endothelium- dependent vasodilation in humans. Circulation. 1997; 95:1119-21

[10] Bellamy MF, McDowell IFW, Ramsey MW et al. Hyperhomocysteinemia after an oral methionine load acutely impairs endothelial function in healthy adults. Circulation. 1998; 98:1848-52

[11] Austin RC, Lentz SR, Werstuck GH. Role of hyperhomocysteinemia in endothelial dysfunction and atherothrombotic disease. Cell Death Differ. 2004; 11: S56-64

[12] Di Simone N, Maggiano N, Caliandro D et al. Homocysteine induces trophoblast cell death with apoptotic features. Biol. Reprod. 2003; 69: 1129-34

[13] Hultberg B, Andersson A, Isaksson A. Metabolism of homocysteine, its relation to the other cellular thiols and its mechanism of cell damage in a cell culture line (human histiocytic cell line U-937). Biochem. Biophys. Acta 1995; 1269: 6-12

[14] Faeh D, Chiolero A, Paccaud F. Homocysteine as a risk factor for cardiovascular disease: Should we (still) worry about it? Swiss Medical Weekly. 2006; 136: 74556

[15] Ueland PM, Refsum H, Beresford SA et al. The controversy over homocysteine and cardiovascular risk. Am J Clin Nutr. 2000; 72: 324-32

[16] Kaplan ED. Association between homocysteine levels and risk of vascular events. Drugs Today. 2003; 39: 175-92 
[17] Cacciapuoti F. Hyper-homocysteinemia: a novel risk factor or a powerful marker for cardiovascular diseases? Pathogenetic and therapeutical uncertainties. J Thromb Thrombolysis. 2011 Jan 14. [Epub ahead of print]

[18] Clarke R, Collins R, Lewington S et al. Homocysteine and risk of ischemic heart disease and stroke: A meta-analysis. JAMA. 2002; 288: 2015-22

[19] Mei W, Rong Y, Jinming L et al. Effect of homocysteine interventions on the risk of cardiocerebrovascular events: A meta-analysis of randomised controlled trials. Int J Clin Pract. 2010; 64: 208-15

[20] Graeme J. B vitamins in patients with recent transient ischaemic attack or stroke in the VITAmins TO prevent stroke (VITATOPS) trial: A randomised, double-blind, parallel, placebo-controlled trial. Lancet Neurol. 2010; 9: 855-65

[21] Bazzano LA, Reynolds K, Holder KN et al. Effect of folic acid supplementation on risk of cardiovascular diseases: A meta-analysis of randomized controlled trials. JAMA. 2006; 296: 2720-6

[22] Kim W, Pae Y. Involvement of N-methyl-D-aspartate receptor and free radical in homocysteine-mediated toxicity on rat cerebellar granule cells in culture. Neurosci Lett. 1996; 216: 117-20.

[23] Moore P, El-sherbeny A, Roon P, Schoenlein PV, Ganapathy V, Smith SB. Apoptotic cell death in the mouse retinal ganglion cell layer is induced in vivo by the excitatory amino acid homocysteine. Exp Eye Res. 2001; 73: 45-57.

[24] Ganapathy PS, White RE, Ha Y, Bozard BR, McNeil PL, Caldwell RW, Kumar S, Black SM, Smith SB. The Role of N-Methyl-D-Aspartate Receptor Activation in Homocysteine-Induced Death of Retinal Ganglion Cells. IOVS 2011 Mar 24. [Epub ahead of print].

[25] Herrmann W, Obeid R. Homocysteine: A biomarker in neurodegenerative diseases. Clin Chem Lab Med. 2011; 49: 435-41

[26] Hin H, Clarke R, Sherliker P et al. Clinical relevance of low serum vitamin B12 concentrations in older people: The banbury B12 study. Age Ageing. 2006; 35: 41622

[27] Kim J, Park MH, Kim E et al. Plasma homocysteine is associated with the risk of mild cognitive impairment in an elderly korean population. J Nutr. 2007; 137: 2093-7

[28] Leblhuber F, Schroecksnadel K, Beran-Praher M et al Polyneuropathy and dementia in old age: Common inflammatory and vascular parameters. J Neural Transm. 2011 [Epub ahead of print].

[29] Smith AD, Smith SM, de Jager CA et al. Homocysteine-lowering by b vitamins slows the rate of accelerated brain atrophy in mild cognitive impairment: A randomized controlled trial. PLoS ONE. 2010; 5:1-10

[30] Tyagi SC. Homocysteine redox receptor and regulation of extracellular matrix components in vascular cells. Am J Physiol - Cell Physiol. 1998; 274: C396-405.

[31] Bescond A, Augier T, Chareyre C et al. Influence of homocysteine on matrix metalooproteinase-2: activation and activity. Biochem Biophys Res Commun 1999: 263; 205-16 
[32] Sood HS, Cox MJ, Tyagi SC. Generation of Nitrotyrosine Precedes Activation of Metalloproteinase in Myocardium of Hyperhomocysteinemic Rats. Antiox Redox Signal. 2002: 4; 799-804

[33] Moshal KS, Sen U, Tyagi N et al. Regulation of homocysteine-induced MMP-9 by ERK1/2 pathway Am J Physiol Cell Physiol, 2006: 290; C883-C891

[34] Flammer J, Orgul S, Costa VP et al. The impact of ocular blood flow in glaucoma. Prog Retin Eye Res 2002: 21:359-93

[35] Hayreh SS: Blood flow in the optic nerve head and factors that may influence it. Prog Retin Eye Res 2001: 20:595-624

[36] Finkelstein JD: The metabolism of homocysteine: pathways and regulation. Eur J Pediatr 1998: 157; 40-44

[37] Brunelli T, Prisco D, Fedi S et al. High prevelance of mild hyperhomocysteinemia in patients with abdominal aortic aneurysm. J Vasc Surg 2000: 32; 531-536

[38] Moghimi S, Najmi Z, Faghihi H et al. Hyperhomocysteinemia and central retinal vein occlusion in Iranian population. Int Ophthalmol. 2008; 28; 23-8

[39] Narayanasamy A, Subramaniam B, Karunakaran C et al. Hyperhomocysteinemia and low methionine stress are risk factors for central retinal venous occlusion in an Indian population. IOVS 2007: 48; 1441-6

[40] Glueck CJ, Ping W, Hutchins R et al. Ocular vascular thrombotic events: central retinal vein and central retinal artery occlusions. Clin Appl Thromb Hemost. 2008: $14 ; 286-94$

[41] Ferrazzi P, Di Micco P, Quaglia I et al. Homocysteine, MTHFR C677T gene polymorphism, folic acid and vitamin B 12 in patients with retinal vein occlusion. Thromb J. 2005: 7; 3-13

[42] Gao W, Wang YS, Zhang P et al. Hyperhomocysteinemia and low plasma folate as risk factors for central retinal vein occlusion: a case-control study in a Chinese population. Graefes Arch Clin Exp Ophthalmol. 2006: 244; 1246-9

[43] Chua B, Kifley A, Wong TY et al. Homocysteine and retinal vein occlusion: a population-based study. Am J Ophthalmol. 2005: 139; 181-2

[44] McGimpsey SJ, Woodside JV, Cardwell C et al. Homocysteine, methylenetetrahydrofolate reductase C677T polymorphism, and risk of retinal vein occlusion: a meta-analysis. Ophthalmology. 2009: 116; 1778-87

[45] Weger M, Stanger O, Deutschmann H, Leitner FJ, Renner W, Schmut O, Semmelrock J, Haas A. The role of hyperhomocysteinemia and methylenetetrahydrofolate reductase (MTHFR) C677T mutation in patients with retinal artery occlusion. Am J Ophthalmol. 2002: 134; 57-61

[46] Marcucci R, Sodi A, Giambene B et al. Cardiovascular and thrombophilic risk factors in patients with retinal artery occlusion. Blood Coagul Fibrinolysis. 2007: 18; 321-6

[47] Martin SC, Rauz S, Marr JE et al. Plasma total homocysteine and retinal vascular disease. Eye 2000: 14; 590-3

[48] Chua B, Kifley A, Wong TY et al. Homocysteine and retinal emboli: the Blue Mountains Eye Study. Am J Ophthalmol. 2006; 142: 322-4

[49] Cahill MT, Stinnett SS, Fekrat S. Meta-analysis of plasma homocysteine, serum folate, serum vitamin $\mathrm{B}(12)$, and thermolabile MTHFR genotype as risk factors for retinal vascular occlusive disease. Am J Ophthalmol. 2003: 136; 1136-50 
[50] Williams PT. Prospective study of incident age-related macular degeneration in relation to vigorous physical activity during a 7-year follow-up. IOVS. 2009: 50; 101-6.

[51] Magnusson KP, Duan S, Sigurdsson H et al. CFH Y402H confers similar risk of soft drusen and both forms of advanced AMD. PLoS Med. 2006: 3; e5.

[52] Snow KK, Seddon JM. Age-related macular degeneration and cardiovascular disease share common antecedents? Ophthalmic Epidemiol. 1999: 6; 125-43.

[53] Axer-Siegel R, Bourla D, Ehrlich R et al. Association of neovascular age-related macular degeneration and hyperhomocysteinemia. Am J Ophthalmol. 2004: 137; 84-9.

[54] Javadzadeh A, Ghorbanihaghjo A, Bahreini E. Plasma oxidized LDL and thiolcontaining molecules in patients with exudative age-related macular degeneration. Molecular Vis. 2010; 16: 2578-84

[55] Coral K, Raman R, Rathi S et al. Plasma homocysteine and total thiol content in patients with exudative age-related macular degeneration. Eye. 2006; 20: 203-7

[56] Klein BEK, Knudtson MD, Tsai MY et al. The relation of markers of inflammation and endothelial dysfunction to the prevalence and progression of diabetic retinopathy: Wisconsin epidemiologic study of diabetic retinopathy. Arch Ophthalmol. 2009; 127: $1175-82$

[57] Hoogeveen EK, Kostense PJ, Eysink PE et al. Hyperhomocysteinemia is associated with the presence of retinopathy in type 2 diabetes mellitus: the Hoorn study. Arch Intern Med. 2000 23; 160: 2984-90

[58] Brazionis L, Rowley K Sr, Itsiopoulos C et al. Homocysteine and diabetic retinopathy. Diabetes Care. 2008; 31: 50-6.

[59] Aydin E, Demir HD, Ozyurt $\mathrm{H}$ et al. Association of plasma homocysteine and macular edema in type 2 diabetes mellitus. Eur J Ophthalmol. 2008; 18: 226-32

[60] Goldstein M, Leibovitch I, Yeffimov I et al. Hyperhomocysteinemia in patients with diabetes mellitus with and without diabetic retinopathy. Eye 2004; 18: 460-5

[61] Aydemir O, Türkçüoğlu P, Güler $\mathrm{M}$ et al. Plasma and vitreous homocysteine concentrations in patients with proliferative diabetic retinopathy. Retina. 2008; 28: $741-3$

[62] Sun J, Xu Y, Zhu Y et al. The relationship between MTHFR gene polymorphisms, plasma homocysteine levels and diabetic retinopathy in type 2 diabetes mellitus. Chin Med J. 2003; 116: 145-7

[63] Wiltshire EJ, Mohsin F, Chan A. Methylenetetrahydrofolate reductase and methionine synthase reductase gene polymorphisms and protection from microvascular complications in adolescents with type 1 diabetes. Pediatr Diabetes. 2008; 9: 348-53

[64] Ukinc K, Ersoz HO, Karahan C, et al. Methyltetrahydrofolate reductase C677T gene mutation and hyperhomocysteinemia as a novel risk factor for diabetic nephropathy. Endocrine. 2009; 36: 255-61.

[65] Hayreh SS. Acute ischemic disorders of the optic nerve: pathogenesis, clinical manifestations and management. Ophthal Clin North Am 1996; 9: 407-42

[66] Pianka P, Almog Y, Man O, et al. Hyperhomocysteinemia in patients with non-arteritic anterior ischaemic neuropathy, central retinal artery occlusion and central retinal vein occlusion. Ophthalmology 2000; 107: 1588-92 
[67] Giambene B, Sodi A, Sofi F et al. Evaluation of traditional and emerging cardiovascular risk factors in patients with non-arteritic anterior ischemic optic neuropathy: A case-control study. Graefe Arch Clin Exp Ophthal. 2009; 247: 693-7

[68] Weger M, Stanger O, Deutschmann H, et al. Hyperhomocysteinaemia, but not MTHFR C677T mutation, as a risk factor for nonarteritic ischemic optic neuropathy. $\mathrm{Br} \mathrm{J}$ Ophthalmol 2001; 85: 803-6

[69] Kawasaki A, Purvin VA, Burgett RA. Hyperhomocysteinaemia in young patients with non-arteritic anterior ischaemic optic neuropathy. Br J Ophthalmol 1999; 83: 1287-90

[70] Biousse V, Kerrison JB, Newman NJ. Is non-arteritic anterior ischaemic optic neuropathy related to homocysteine? Br J Ophthalmol 2000; 84: 555

[71] Imrie FR, Hammer HM, Jay JL. Bilateral ocular ischaemic syndrome in association with hyperhomocysteinaemia. Eye. 2002; 16: 497-500.

[72] Puustjärvi T, Blomster $\mathrm{H}$, Kontkanen $\mathrm{M}$ et al. Plasma and aqueous humour levels of homocysteine in exfoliation syndrome. Graefes Arch Clin Exp Ophthalmol. 2004; 242: 749-54.

[73] Tranchina L, Centofanti M, Oddone F et al. Levels of plasma homocysteine in pseudoexfoliation glaucoma. Graefes Arch Clin Exp Ophthalmol 2011 249; 443-448

[74] Turgut B, Kaya M, Arslan S et al. Levels of circulating homocysteine, vitamin B6, vitamin B12, and folate in different types of open-angle glaucoma Clin Interventions Aging 2010:5 133-9

[75] Clement CI, Goldberg I, Healey P et al Plasma Homocysteine, MTHFR Gene Mutation, and Open-angle Glaucoma J Glaucoma 2009: 18; 73-8

[76] Roedl JB, Bleich S, Reulbach U et al. Homocysteine in tear fluid of patients with pseudoexfoliation glaucoma. J Glaucoma. 2007; 16: 234-9

[77] Roedl JB, Bleich S, Reulbach U et al. Vitamin deficiency and hyperhomocysteinemia in pseudoexfoliation glaucoma. J Neural Transm. 2007; 114: 571-5

[78] Cumurcu T, Sahin S, Aydin E. Serum homocysteine, vitamin B12 and folic acid levels in different types of glaucoma. BMC Ophthalmol. 2006; 6: 6 .

[79] Saricaoglu MS, Karakurt A, Sengun A et al. Plasma homocysteine levels and vitamin B status in patients with Pseudoexfoliation syndrome. Saudi Med J. 2006; 27: 833-7.

[80] Turacli ME, Tekeli O, O"zdemir F, et al. Methylenetetrahydrofolate reductase $677 \mathrm{C}-\mathrm{T}$ and homocysteine levels in Turkish patients with pseudoexfoliation. Clin Exp Ophthalmol. 2005; 33: 505-8.

[81] Altinta O, Maral H, Yüksel N et al. Homocysteine and nitric oxide levels in plasma of patients with pseudoexfoliation syndrome, pseudoexfoliation glaucoma, and primary open-angle glaucoma. Graefes Arch Clin Exp Ophthalmol. 2005; 243: 677-83

[82] Bleich S, Roedl J, Von Ahsen N, et al. Elevated homocysteine in aqueous humor of patients with pseudoexfoliation glaucoma. Am J Ophthalmol. 2004; 138: 162-4

[83] Leibovitch I, Kurtz S, Shemesh G et al. Hyperhomocystinemia in Pseudoexfoliation Glaucoma J Glaucoma 12: 36-9

[84] Vessani RM, Ritch R, Liebmann JM, et al. Plasma homocysteine is elevated in patients with exfoliation syndrome. Am J Ophthalmol. 2003; 136: 41-6

[85] Bleich S, Jünemann A, von Ahsen $N$ et al. Homocysteine and risk of open-angle glaucoma. J Neural Transm. 2002; 109:1499-504 
[86] Mitchell P, Wang JJ, Smith W. Association of pseudoexfoliation syndrome with increased vascular risk. Am J Ophthalmol 1997; 124: 685-687

[87] Koliakos GG, Konstas AG, Schlötzer-Schrehardt U et al. Endothelin-1 concentration is increased in aqueous humour of patients with exfoliation syndrome. $\mathrm{Br} J$ Ophthalmol 2004: 88; 523-7

[88] Linner E, Popovic V, Gottfries CG et al The exfoliation syndrome in cognitive impairment of cerebrovascular or Alzheimer's type. Acta Ophthalmolo Scand 2001: $79 ; 283-5$

[89] Leblhuber F, Walli J, Artner-Dworzak E et al Hyperhomocysteinemia in dementia. J Neural Transm 2000: 1071469 - 74

[90] Micheal S, Qamar R, Akhtar F et al. MTHFR gene C677T and A1298C polymorphisms and homocysteine levels in primary open angle and primary closed angle glaucoma. Mol Vis. 2009;15: 2268-78.

[91] Roedl JB, Bleich S, Schlötzer-Schrehardt U et al. Increased homocysteine levels in tear fluid of patients with primary open-angle glaucoma. Ophthalmic Res. 2008; 40: 24956

[92] Roedl JB, Bleich S, Reulbach U et al. Homocysteine levels in aqueous humor and plasma of patients with primary open-angle glaucoma. J Neural Transm. 2007; 114: $445-50$

[93] Wang G, Medeiros FA, Barshop BA et al. Total plasma homocysteine and primary open-angle glaucoma. Am J Ophthalmol. 2004; 137: 401-6

[94] Rössler CW, Baleanu D, Reulbach U et al. Plasma homocysteine levels in patients with normal tension glaucoma. J Glaucoma. 2010; 19: 576-80

[95] Fan BJ, Liu K, Wang DY et al. Association of polymorphisms of tumor necrosis factor and tumor protein p53 with primary open-angle glaucoma. IOVS 2010; 51: 4110-6

[96] Fingert JH, Kwon YH, Moore PA et al. The C677T variant in the methylenetetrahydrofolate reductase gene is not associated with disease in cohorts of pseudoexfoliation glaucoma and primary open-angle glaucoma patients from Iowa. Ophthalmic Genet. 2006; 27: 39-41

[97] Mossbock G, Weger M, Faschinger C et al. Methylenetetrahydrofolatereductase (MTHFR) 677C>T polymorphism and open angle glaucoma. Mol Vis. 2006 17; 12: 356-9

[98] Fan BJ, Chen T, Grosskreutz C et al. Lack of association of polymorphisms in homocysteine metabolism genes with pseudoexfoliation syndrome and glaucoma. Mol Vis. 2008; 14: 2484-91

[99] Michael S, Qamar R, Akhtar F et al. C677T polymorphism in the methylenetetrahydrofolate reductase gene is associated with primary closed angle glaucoma. Mol Vis. 2008; 14: 661-5

[100] Zetterberg M, Tasa G, Palmér MS et al. Methylenetetrahydrofolate reductase genetic polymorphisms in patients with primary open-angle glaucoma. Ophthalmic Genet. 2007; 28: 47-50

[101] Mabuchi F, Tang S, Kashiwagi K et al. Methylenetetrahydrofolate reductase gene polymorphisms c.677C/T and c.1298A/C are not associated with open angle glaucoma. Mol Vis. 2006; 12: 735-9 
[102] Jünemann AG, von Ahsen $N$, Reulbach $U$ et al. C677T variant in the methylentetrahydrofolate reductase gene is a genetic risk factor for primary openangle glaucoma. Am J Ophthalmol. 2005; 139: 721-3

[103] Woo SJ, Kim JY, Kim DM et al. Investigation of the association between $677 \mathrm{C}>\mathrm{T}$ and $1298 \mathrm{~A}>\mathrm{C}$ 5,10-methylenetetra- hydrofolate reductase gene polymorphisms and normal-tension glaucoma. Eye. 2009; 23: 17-24 


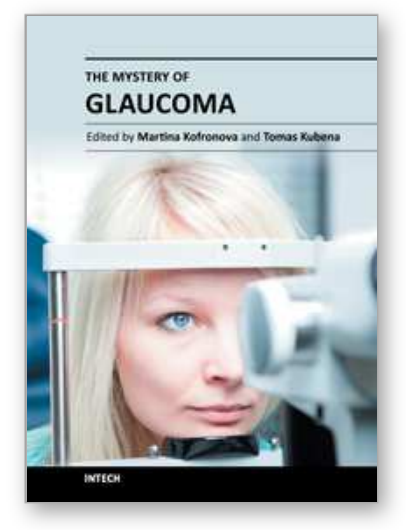

\author{
The Mystery of Glaucoma \\ Edited by Dr. Tomas Kubena
}

ISBN 978-953-307-567-9

Hard cover, 352 pages

Publisher InTech

Published online 06, September, 2011

Published in print edition September, 2011

Since long ago scientists have been trying hard to show up the core of glaucoma. To its understanding we needed to penetrate gradually to its molecular level. The newest pieces of knowledge about the molecular biology of glaucoma are presented in the first section. The second section deals with the clinical problems of glaucoma. Ophthalmologists and other medical staff may find here more important understandings for doing their work. What would our investigation be for, if not owing to the people's benefit? The third section is full of new perspectives on glaucoma. After all, everybody believes and relies - more or less - on bits of hopes of a better future. Just let us engage in the mystery of glaucoma, to learn how to cure it even to prevent suffering from it. Each information in this book is an item of great importance as a precious stone behind which genuine, through and honest piece of work should be observed.

\title{
How to reference
}

In order to correctly reference this scholarly work, feel free to copy and paste the following:

Mustafa R Kadhim and Colin I Clement (2011). Homocysteine in the Pathogenesis of Chronic Glaucoma, The Mystery of Glaucoma, Dr. Tomas Kubena (Ed.), ISBN: 978-953-307-567-9, InTech, Available from: http://www.intechopen.com/books/the-mystery-of-glaucoma/homocysteine-in-the-pathogenesis-of-chronicglaucoma

\section{INTECH}

open science | open minds

\author{
InTech Europe \\ University Campus STeP Ri \\ Slavka Krautzeka 83/A \\ 51000 Rijeka, Croatia \\ Phone: +385 (51) 770447 \\ Fax: +385 (51) 686166 \\ www.intechopen.com
}

\author{
InTech China \\ Unit 405, Office Block, Hotel Equatorial Shanghai \\ No.65, Yan An Road (West), Shanghai, 200040, China \\ 中国上海市延安西路65号上海国际贵都大饭店办公楼405单元 \\ Phone: +86-21-62489820 \\ Fax: +86-21-62489821
}


(C) 2011 The Author(s). Licensee IntechOpen. This chapter is distributed under the terms of the Creative Commons Attribution-NonCommercialShareAlike-3.0 License, which permits use, distribution and reproduction for non-commercial purposes, provided the original is properly cited and derivative works building on this content are distributed under the same license. 